\title{
Blindness and visual impairment in retinitis pigmentosa: a Cameroonian hospital-based study
}

This article was published in the following Dove Press journal:

Clinical Ophthalmology

23 June 2010

Number of times this article has been viewed

\author{
André Omgbwa Eballe' \\ Godefroy Koki ${ }^{2}$ \\ Claude Bernard Emche ${ }^{2}$ \\ Lucienne Assumpta Bella ${ }^{2}$ \\ Jeanne Mayouego Kouam² \\ Justin Melong 3 \\ 'Faculty of Medicine and \\ Pharmaceutical Sciences, University \\ of Douala; ${ }^{2}$ Faculty of Medicine and \\ Biomedical Sciences, University of \\ Yaoundé; ${ }^{3}$ Translation Unit, Ministry \\ of Public Health, Yaoundé, Cameroon
}

Correspondence: André Omgbwa Eballe Ophthalmology Unit,

Gyneco-Obstetric and Pediatric Hospital of Yaoundé, PO Box 4362, Yaoundé,

Cameroon

Tel + II 23799654468

Fax + II 237222 I 2430

Email andyeballe@gmail.com
Aim: We performed a retrospective, analytical study in February 2010 on all retinitis pigmentosa cases seen during ophthalmologic consultation at the Gyneco-Obstetrics and Pediatric Hospital of Yaounde between March 2002 and December 2009 (82 months). The aim of this research was to determine the significance of blindness and visual impairment associated with retinitis pigmentosa in Cameroon.

Results: Forty cases were reported, corresponding to a hospital prevalence of 1.6/1000 (21 men and 19 women). The average age of the patients was $43.3 \pm 18$ years, ranging between 6 and 74 years. Bilateral blindness and low vision was noted in $30 \%$ and $27.5 \%$ of patients, respectively. The average age of patients with low vision was $40.38 \pm 16.27$ years and the average age of those with bilateral blindness was $51.08 \pm 15.79$ years. Retinitis pigmentosa was bilateral in all cases and isolated (without any eye or general additional disease) in $67.5 \%$ of cases.

Conclusion: Visual impairment is common and becomes even more severe with aging. Patients should be screened to enable them to benefit from management focusing on both appropriate treatment and genetic counseling.

Keywords: retinitis pigmentosa, Cameroon, blindness, Yaoundé

\section{Introduction}

Retinitis pigmentosa is a genetic disorder with diffuse retinal dystrophy which, in most cases, primarily affects the rods initially, with subsequent degeneration of cones. Its prevalence ranges from $1 / 3000$ to $1 / 5000 .{ }^{1,2}$ Transmission of retinitis pigmentosa is genetic and may be by various modes, ie, autosomal dominant, autosomal recessive, or $\mathrm{X}$-linked recessive. ${ }^{3}$ Retinitis pigmentosa is a leading cause of blindness and incurable visual impairment, owing to its irreversible evolution towards loss of central vision. We undertook this work in order to determine for the first time the significance of blindness and visual impairment associated with retinitis pigmentosa in Cameroon.

\section{Methods}

A retrospective study was carried out on all retinitis pigmentosa cases seen in the outpatients' clinic at the Ophthalmological Unit of the Gyneco-Obstetrics and Pediatric Hospital of Yaoundé between March 2002 and December 2009 (82 months). The files of patients with retinitis pigmentosa were reviewed. The diagnosis of retinitis pigmentosa was made on the basis of an examination of the ocular fundus using a biomicroscope, the three ophthalmoscopic criteria being retinal hyperpigmentation in star clusters (osteoblasts), arterial narrowing, and waxy pallor of the papilla. Far visual acuity on the Snellen scale, intraocular pressure using an air-pulse tonometer, abnormalities in 
the anterior segment, and the ocular fundus of each patient were also noted. Performance of additional examinations, ie, automatic visual field and retinal angiography was not systematic, and few patients, for financial reasons, had visual field assessment. Electroretinography (ERG) and genetic tests were not performed in our study due to the inadequate level of technical expertise at the unit.

The variables analyzed were age, gender, main complaint, far visual acuity, intraocular pressure, ocular fundus, and visual field. The chi-squared test was used for comparison, and was considered significant at $P<0.05$.

The classification of visual impairment was made using the analysis of visual acuity as defined by the World Health Organization, ${ }^{4}$ ie, binocular blindness (visual acuity $<1 / 20$ of the better eye with correction, and low vision (visual acuity $<3 / 10$ and $\geq 1 / 20$ of the better eye with correction). We considered any patient with a corrected visual acuity of the better eye $>3 / 10$ and that of the impaired eye $<1 / 20$ as having monocular blindness.

\section{Results}

Of 24,205 files selected for study, 40 cases of retinitis pigmentosa were identified, corresponding to a hospital prevalence of 1.6/1000. The disease was noted in 21 men and 19 women. The average age of patients was $43.3 \pm 18.2$ years, with a range of 6-74 years. The most represented age group was 41-50 years, which included 11 patients $(27.5 \%)$, followed by patients aged $>60$ years (eight cases, $20 \%$ ), with only four cases $(10 \%)<20$ years. In total, 24 patients $(60 \%)$ were $>40$ years (Table 1$)$.

The main complaint was a drop in visual acuity, which was found in 35 patients $(87.5 \%)$, followed by night blindness in 28 patients $(70 \%)$. It should be noted that a single patient could have several reasons for consultation. With regard to family history, we noted 10 cases $(25 \%)$ of a history of blindness in relatives, but the cause of this blindness was unknown to the patient or the family. No case of parental consanguinity was reported. In addition, retinitis pigmentosa

Table I Age distribution of patients with retinitis pigmentosa

\begin{tabular}{lll}
\hline Age (years) & $\mathbf{n}$ & $\%$ \\
\hline$<10$ & $\mathrm{I}$ & 2.5 \\
$1 \mathrm{I}-20$ & 3 & 7.5 \\
$21-30$ & 7 & 17.5 \\
$31-40$ & 5 & 12.5 \\
$41-50$ & $1 \mathrm{I}$ & 27.5 \\
$51-60$ & 5 & 12.5 \\
$>60$ & 8 & 20.0 \\
Total & 40 & 100 \\
\hline
\end{tabular}

was not diagnosed in siblings of affected patients, in cases where brothers and/or sisters attended an ophthalmologic consultation requested by the attending physician.

The analysis of visual acuity revealed binocular blindness in 12 patients $(30 \%)$ and low vision in 11 cases $(27.5 \%$, see Figure 1). One case of monocular blindness was noted in a patient with a unilateral macular hole.

Six of 11 patients $(54.54 \%)$ with low vision were older than 40 years and nine of 12 cases $(75 \%)$ of bilateral blindness were recorded in patients older than 40 years (Table 2). The average age of patients with low vision was $40.38 \pm$ 16.27 years and that of patients with bilateral blindness was $51.08 \pm 15.79$ years.

The average intraocular pressure observed was $14.30 \pm$ $2.86 \mathrm{mmHg}$ and $14.83 \pm 5.24 \mathrm{mmHg}$ in the right eye and left eye, respectively. The intraocular pressure was above normal $(21 \mathrm{mmHg}$ ) in three eyes from three different patients.

Retinitis pigmentosa was bilateral in all our patients, and isolated (without any other eye or additional disease) in 27 cases $(67.5 \%)$. The major associated pathologies were cataract (four cases), chronic open angle glaucoma (three cases), age-related macular degeneration (ARMD, three cases), and high myopia (two cases, Table 3). No deafness was noticed to prompt consideration of Usher syndrome. Table 4 shows that nine of 13 patients $(69.23 \%)$ with related diseases were older than 40 years.

Visual field examination was performed in only 10 patients. All reports on automated perimetry revealed tubular visual fields with absolute annular scotoma.

\section{Discussion}

This study focused on patients treated in a hospital-based ophthalmologic outpatients unit. The hospital prevalence of retinitis pigmentosa (1.6/1000) would clearly not be representative of the entire Cameroonian population. In Caucasian countries, the prevalence in general population
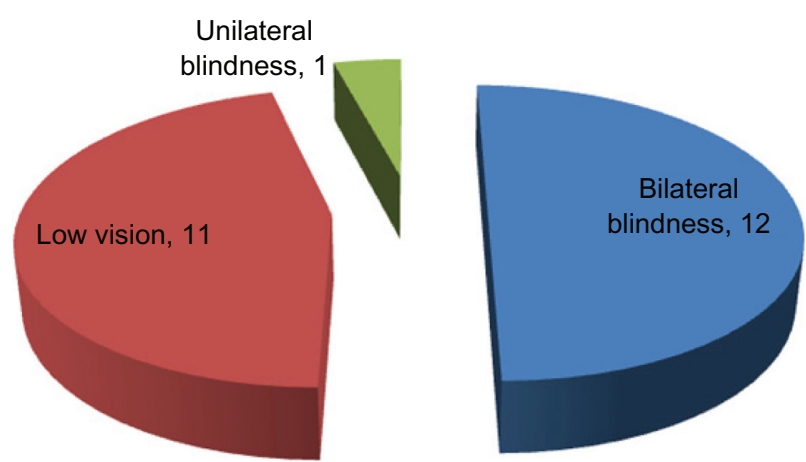

Figure I Distribution of blindness and low vision. 
Table 2 Distribution of blindness and low vision according to patient age

\begin{tabular}{|c|c|c|c|}
\hline \multirow{2}{*}{$\begin{array}{l}\text { Age } \\
\text { (years) }\end{array}$} & \multicolumn{3}{|c|}{ Visual pathology } \\
\hline & $\begin{array}{l}\text { Bilateral } \\
\text { blindness } \\
\text { n (\%) }\end{array}$ & $\begin{array}{l}\text { Low vision } \\
\text { n (\%) }\end{array}$ & $\begin{array}{l}\text { Unilateral } \\
\text { blindness } \\
\text { n (\%) }\end{array}$ \\
\hline$<10$ & $0(0.00)^{*}$ & $0(0.00)^{*}$ & $0(0.00)^{*}$ \\
\hline $1 \mathrm{I}-20$ & $0(0.00)$ & I (33.33) & $0(0.00)$ \\
\hline $21-30$ & $2(28.57)$ & I (I4.29) & I (I4.29) \\
\hline $31-40$ & I $(20.00)$ & $3(60.00)$ & $0(0.00)$ \\
\hline $4 I-50$ & $2(18.18)$ & $3(27.27)$ & $0(0.00)$ \\
\hline $5 I-60$ & $3(60.00)$ & I (20.00) & $0(0.00)$ \\
\hline$>60$ & $4(50.00)$ & $2(25.00)$ & $0(0.00)$ \\
\hline Total & $12(30.00)$ & II (27.50) & I $(2.50)$ \\
\hline
\end{tabular}

studies is much lower, eg, 1/4756 in Maine, US ${ }^{5}$ and 1/3943 in Denmark. ${ }^{6}$ However, our prevalence is similar to that obtained by Kaya-Ganziami et al in a Congolese hospital. ${ }^{7}$

In our series, retinitis pigmentosa indiscriminately affected men and women $(P>0.05)$, in contrast with the findings of Kaya-Ganziami et al in Congo and Ukponmwan et al in Nigeria, where a male predominance of $63.6 \%$ and $66.6 \%$, respectively, has been reported. ${ }^{7,8}$

It is generally recognized that night blindness is one of the commonest complaints in retinitis pigmentosa, ${ }^{7,9-11}$ and the results of our study are consistent with this observation. Indeed, a drop in visual acuity and night blindness were the main reasons for consultation in our study. In addition, it should be noted that classical night blindness is often poorly recognized in childhood, and might be discovered only when in-depth investigations are conducted. Our series included few children, but this would not affect the conclusion we arrived at, ie, that a drop in visual acuity was a major cause of consultation in this series.

The average patient age of $43.3 \pm 18.2$ years in our series is older than that found by Ukponmwan et al in Nigeria and Tsujikawa et al in Japan, who reported an average age at diagnosis of 36.7 and 35.1 years, respectively. ${ }^{8,12}$ This

Table 3 Distribution of patients according to associated pathologies

\begin{tabular}{lll}
\hline Associated pathologies & $\mathbf{n}$ & $\%$ \\
\hline Cataract & 4 & 10.00 \\
ARMD & 3 & 7.50 \\
Glaucoma & 3 & 7.50 \\
High myopia & 2 & 5.00 \\
Isolated RP & 27 & 67.50 \\
Unilateral macular hole & I & 2.50 \\
Total & 40 & 100.00 \\
\hline
\end{tabular}

Abbreviations: ARMD, age-related macular degeneration; RP, retinitis pigmentosa. difference may be explained by the delayed presentation of our patients, whose first recourse to treatment is often traditional practitioners and a tendency to come to hospital only when low vision and blindness are well advanced. Nevertheless, Grover et al ${ }^{13}$ found in their US series an average age at presentation of 41 years, which is similar to our findings.

In our study, $57.5 \%$ of patients had a significant bilateral decrease of visual acuity at the time of diagnosis (binocular blindness in $30 \%$ and low vision in $27.5 \%$ ). This is similar to the data of Ukponmwan et al who reported binocular blindness in $50 \%$ and low vision in $26.7 \%$ of patients in their Nigerian series, ${ }^{7}$ and is also similar to the findings of Grover et al who reported a visual acuity $<1 / 10$ in $25 \%$ of their patients suffering from retinitis pigmentosa,${ }^{14}$ corresponding to severe low vision or blindness. In our series, the severity of visual impairment appears to be correlated with patient age. The older the subject, the more significant is the functional impairment, and thus we are left with an average age of about 40 years for people with low vision and about 50 years for people with bilateral blindness.

In interpreting these outcomes, it is considered that there is a natural evolution of the disease whereby the patient starts to develop low vision approximately 10 years before becoming totally blind. This is consistent with the findings of a US study by Marmor ${ }^{15}$ who found far visual acuity (interpreted as severe low vision or blindness) to be $<1 / 10$ in more than $50 \%$ of patients with retinitis pigmentosa who were aged over 50 years. The severity of visual impairment also depends on the mode of genetic transmission. In the US, it has been shown that patients with the clinical form of autosomal dominant retinitis pigmentosa suffer less from low vision and blindness compared with those having the $\mathrm{X}$-linked recessive form of the disease..$^{13,16}$ Unfortunately, no genetic study on this issue has ever been carried out in Cameroon where state-of-the-art science is still in its early stages.

Retinitis pigmentosa was isolated in $67.5 \%$ of cases, and no case of Usher syndrome was noted. This is consistent with a report by Kaya-Ganziami et al who found that $72.27 \%$ of cases of retinitis pigmentosa were isolated, ${ }^{7}$ whereas Grover et al ${ }^{13}$ found that only $47 \%$ were isolated. Associated illnesses were found in patients of relatively advanced age. Thus, all cases of cataracts, age-related macular degeneration, and $75 \%$ of glaucoma cases were identified in patients over 40 years. These potentially blinding diseases might worsen the visual prognosis for these patients and consequently affect their quality of life. In the US, Pruett found an association between retinitis pigmentosa and cataracts in $46.4 \%$ of cases,${ }^{17}$ while Auffarth in Germany found this association in $40.7 \%-52.9 \%$ 
Table 4 Distribution of associated pathologies according to patient age

\begin{tabular}{|c|c|c|c|c|c|c|c|c|}
\hline \multirow{2}{*}{$\begin{array}{l}\text { Associated } \\
\text { pathologies* }\end{array}$} & \multicolumn{7}{|c|}{ Age (years) } & \multirow[t]{2}{*}{ Total } \\
\hline & $<10$ & $1 I-20$ & $21-30$ & $31-40$ & $4 I-50$ & $5 I-60$ & $>60$ & \\
\hline Cataract & $0(0.00)$ & $0(0.00)$ & $0(0.00)$ & I (20.00) & I (9.09) & I (20.00) & $\mathrm{I}(\mathrm{I} 2.50)$ & $4(10.00)$ \\
\hline ARMD & $0(0.00)$ & $0(0.00)$ & $0(0.00)$ & $0(0.00)$ & $0(0.00)$ & $0(0.00)$ & $3(37.50)$ & $3(7.50)$ \\
\hline Glaucoma & $0(0.00)$ & $0(0.00)$ & $0(0.00)$ & $0(0.00)$ & I (9.09) & I (20.00) & I (12.50) & $3(7.50)$ \\
\hline High myopia & $0(0.00)$ & $0(0.00)$ & I (I4.29) & I (20.00) & $0(0.00)$ & $0(0.00)$ & $0(0.00)$ & $2(5.00)$ \\
\hline Macular hole & $0(0.00)$ & $0(0.00)$ & I (I4.29) & $0(0.00)$ & $0(0.00)$ & $0(0.00)$ & $0(0.00)$ & I (2.50) \\
\hline
\end{tabular}

$*_{n}(\%)$.

Abbreviation: ARMD, age-related macular degeneration.

of cases, depending on the definition of retinitis pigmentosa used. ${ }^{18}$ Furthermore, Peng in China reported a 2.3\% glaucoma prevalence in a series of patients with retinitis pigmentosa, ${ }^{19}$ which is three times lower than in our series where the prevalence of glaucoma was estimated at $7.5 \%$. This finding provides additional evidence that chronic open angle glaucoma is more common in melanoderma subjects than in any other race. ${ }^{20}$ It is also known that myopia is common in retinitis pigmentosa, especially with the X-linked form, which is an even more frequent cause of consultation. ${ }^{21}$ Myopia comprised 5\% of associated pathologies in our series. The question arises as to whether the cases of high myopia that we recorded might in fact be associated with X-linked retinitis pigmentosa. Local genetic studies of this pathology in the future should throw more light on this issue.

The low rate of visual field assessment would be explained by the poor financial resources of most patients in our catchment area, for whom the cost of this examination amounting to on average 30 Euros, would be prohibitive.

\section{Limitations}

Limitations of this study include the inadequate technical expertise in our unit which prevented some relevant tests being performed, in particular ERGs, which are of paramount importance in patients with retinitis pigmentosa. In the very early stages of the disease, the ERG response is either off or limited to a small photopic b-wave which disappears suddenly. There is no relationship between ERG and visual acuity, in that an ERG may be off in the presence of good central visual acuity. It is possible to conduct this examination even in children aged younger than six years, in whom the visual field is hard to obtain. ${ }^{21}$ On the other hand, owing to the lack of ERG, we were not able to investigate retinitis pigmentosa in apparently healthy family members of affected individuals, which would have enabled us to know more about the mode of transmission of the disease. Fluorescein angiography also has diagnostic and prognostic importance in retinitis pigmentosa, ${ }^{21}$ but is not easily accessible in Cameroon.
Retinitis pigmentosa is not well known to the Cameroon population. Blindness which is not well explained (ie, not cataract or glaucoma) is often attributed to a curse from, for example, a neighbor. Therefore, cases of blindness recorded in the family history of a patient suffering from retinitis pigmentosa do not enable us to make a reliable connection between this disease and other cases of blindness in the family. Consequently, any assumptions about the mode of transmission are questionable. Families are large, and relatives tend not to attend ophthalmologic consultations requested by the physician because of an inability to get time off work, lack of interest, or lack of transport. It is therefore difficult to perform a thorough search for cases of retinitis pigmentosa within the same family and to determine the mode of transmission of the disease by either presumption or by genetic testing.

\section{Conclusion}

Visual impairment in retinitis pigmentosa is very common and becomes even more severe with aging. Concomitant illnesses occur with age which may worsen the visual prognosis. Early screening for the disease may be the best strategy for its management, including both appropriate treatment and genetic counseling (although it has also been shown that more than $50 \%$ of subjects cannot confirm their heredity ${ }^{21}$ ). A study of the general population should be undertaken to identify the real prevalence of retinitis pigmentosa in our area. This research should be coupled with genetic studies in order to determine the mode of transmission, which strongly influences clinical expression of the disease and the visual prognosis.

\section{Disclosure}

The authors report no conflict of interest in this work.

\section{References}

1. Hamel C. Retinitis pigmentosa. Orphanet J Rare Dis. 2006;1:40.

2. Bird AC. Photoreceptor dystrophies. Am J Ophthalmol. 1995;119: 543-562. 
3. Hamel C, Griffoin JM, Bazalgette $\mathrm{CH}$, et al. [Molecular genetics of pigmentary retinopathies: Identification of mutations in CHM, RDS, RHO, RPE65, USH2A and XLRS1 genes]. J Fr Ophtalmol. 2000;23: 10:985-995. French.

4. OMS/AIDE MEMOIRE. La cécité et la déficience visuelle, partie I: Informations générales. Aide mémoire n 142, Février 1997.

5. Bunker CH, Berson EL, Bromley WC, Hayes RP, Roderick TH. Prevalence of retinitis pigmentosa in Maine. Am J Ophthalmol. 1984;97: 357-365.

6. Haim M. Epidemiology of retinitis pigmentosa in Denmark. Acta Ophthalmol Scand. 2002;233 Suppl:1-34.

7. Kaya-Ganziami G, Nkoua JL, Mayanda HF, Makita C, MbadingaMupangu $\mathrm{H}$. La rétinite pigmentaire: à propos de 22 cas observés à Brazzaville. Médecine d'Afrique Noire. 1994;41:297-299.

8. Ukponmwan CU, Atamah A. Retinitis pigmentosa in Benin, Nigeria. East Afr Med J. 2004;81:254-257.

9. Hruby K. Retinitis pigmentation. Chibret J Ophthalmol. 1983;1: 9-21.

10. Noble KG. Hereditary chorioretinal dystrophy. Freeman WR, editor. Practical Atlas of Retinal Disease and Therapy. 2nd edition. Philadelphia, PA: Lippincott-Raven Publishers: 1998.

11. Heckenlively JR, Yoser SL, Friedman LH, Oversier JJ. Clinical findings and common symptoms in retinitis pigmentosa. Am J Ophthalmol. 1988;105:504-511.
12. Tsujikawa M, Wada Y, Sukegawa M, et al. Age at onset curves of retinitis pigmentosa. Arch Ophthalmol. 2008;126:337-340.

13. Grover S, Fishman GA, Alexander KR, et al. Visual acuity impairment in patients with retinitis pigmentosa. Ophthalmology. 1996;103: 1593-1600.

14. Grover S, Fishman GA, Anderson RJ, et al. Visual acuity impairment in patients with retinitis pigmentosa at age 45 years or older. Ophthalmology. 1999;106:1780-1785.

15. Marmor MF. Visual loss in retinitis pigmentosa. Am J Ophthalmol. 1990;89:692-698.

16. Pearlman JT. Mathematical models of retinitis pigmentosa: A study of the rate of progress in the different genetic forms. Trans Am Ophthalmol Soc. 1979;77:643-656.

17. Pruett RC. Retinitis pigmentosa: Clinical observations and correlations. Trans Am Ophthalmol Soc. 1983;81:693-735.

18. Auffarth GU, Tetz MR, Krastel H, Blankenagel A, Völcker H E. Complicated cataracts in various forms of retinitis pigmentosa. Type and incidence. Ophthalmology. 1997;94:642-646.

19. Peng DW. Retinitis pigmentosa associated with glaucoma. Zhonghua Yan Ke Za Zhi. 1991;27:262-264.

20. Hamard H. Décision en Ophtalmologie. Maloine, France: Vigot publishers. 1993:80-98.

21. Godde-Jolly D, Dufier JL. Ophtalmologie Pédiatrique. Paris, France: Masson publishers; 1992:259-264.
Clinical Ophthalmology

\section{Publish your work in this journal}

Clinical Ophthalmology is an international, peer-reviewed journal covering all subspecialties within ophthalmology. Key topics include: Optometry; Visual science; Pharmacology and drug therapy in eye diseases; Basic Sciences; Primary and Secondary eye care; Patien Safety and Quality of Care Improvements. This journal is indexed on

Submit your manuscript here: http://www.dovepress.com/clinical-ophthalmology-journal

\section{Dovepress}

PubMed Central and CAS, and is the official journal of The Society of Clinical Ophthalmology (SCO). The manuscript management system is completely online and includes a very quick and fair peer-review system, which is all easy to use. Visit http://www.dovepress.com/ testimonials.php to read real quotes from published authors. 